\title{
Economics of energy storage technology in active distribution networks
}

\author{
Jiongcong CHEN ${ }^{1,2}$, Xudong SONG ${ }^{2}$
}

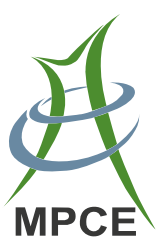

\begin{abstract}
An economic and environmental evaluation of active distribution networks containing lithium ion batteries (Li-ion), sodium sulfur batteries $(\mathrm{NaS})$ and vanadium redox flow batteries (VRB) was carried out using the EnergyPLAN software. The prioritization schemes of the combination of energy storage systems and intermittent energy systems were studied technically and economically based on some specific situations of the grid integrated with wind power. The results suggest that the technical and economic optimal intermittent energy-storage capacity ratio was 2:1 in predetermined energy system scenarios. Liion batteries storage system performed the best in critical excess electricity production (CEEP) absorption, energy saving and emission reduction while $\mathrm{NaS}$ batteries storage system was the most competitive among the three due to its cheaper costs.
\end{abstract}

Keywords Active distribution networks, Intermittent power sources, Battery energy storage, Economy, Optimization

CrossCheck date: 30 March 2015

Received: 23 September 2014/Accepted: 6 August 2015/Published online: 5 November 2015

(C) The Author(s) 2015. This article is published with open access at Springerlink.com

$\triangle$ Jiongcong CHEN

chenjiongcong_ee@163.com

1 South China University of Technology, Guangzhou 510640, Guangdong, China

2 Electric Power Research Institute of Guangdong Power Grid Co. Ltd., Guangzhou 510080, Guangdong, China

\section{Introduction}

Grid connection of large-scale intermittent power sources is an important method for power system restructuring in China. Energy storage systems effectively suppress the fluctuation of intermittent power sources and are therefore an important method to promote the greater use of largescale intermittent power sources.

However, the high cost of battery energy storage systems is one of negative factors for their commercial use. For example, the cost of batteries was about $20 \%$ to $30 \%$ of the total cost of the wind and solar storage integrated demonstration project in Zhangbei, China [1], although the prices have already dropped a lot since building Zhangbei project. It is crucial to optimize the type and capacity of the batteries to reduce the cost of the energy storage systems.

Currently, the economics of the power sources in an active distribution network are directly determined by the energy storage systems. However, it is difficult to evaluate the energy storage systems used in an active distribution network. The EnergyPLAN software can analyze and compare the performance of different energy systems, which are based on fossil fuels, nuclear fuels and renewable energy [2], with one-hour resolution. When the characterization of a reference energy system is completed by the EnergyPLAN software, another energy system can be quickly and easily analyzed through the model, which keeps continuity and consistency. Presently, the software has been used to simulate a $100 \%$ renewable energy system for Mljet island of Croatia [3, 4] and for the entire country of Denmark [5], a large-scale wind power network [6, 7], the optimal combination of renewable energy sources [8], excess power management [9], vehicle-to-grid (V2G) and other technologies to balance a wind power network [10], 
the potential role of fuel cells and batteries [11] and the role of electricity storage [12].

Therefore, this paper considers the technical and economic performance of the lithium ion batteries, sodiumsulphur batteries and vanadium redox flow batteries in active distribution networks using the EnergyPLAN software. These kinds of batteries were simulated in specific configurations with grid-connected solar and wind generation, according to the technical and economic characteristic of the energy sources and energy storage devices, and optimal combinations were explored.

\section{Active distribution networks and energy systems}

\subsection{Characteristics of active distribution networks}

The definition of active distribution networks has been proposed by the CIGRE C6.11 group, and its technical content can be defined as: "active distribution networks have systems in place to control a combination of distributed energy resources (DERs), defined as generators, loads and storage. Distribution system operators (DSOs) have the possibility of managing the electricity flows using a flexible network topology. DERs take some degree of responsibility for system support, which will depend on a suitable regulatory environment and connection agreement" [13]. Therefore, compared with a passive distribution networks, an active distribution network is a new form of distribution network, with a specific technical goal. It can achieve both energy efficiency and economic benefits.

\subsection{Energy systems based on active distribution networks}

The active and reactive power of battery energy storage can be controlled through four-quadrant power conversion systems, and used for many demand-side power management applications. For example, with a suitable control system, battery energy storage can reduce the difference between on-peak and off-peak demand, and improve power quality to increase the efficiency of electrical equipment which will reduce their energy consumption. Battery energy storage can also increase the application of renewable energy by reducing the effects of intermittency on the distribution network, particularly through active voltage regulation. Responsive energy storage systems, such as batteries, can also improve the system stability, by providing ancillary services to help maintain the frequency of the system and compensate load fluctuations and generator and transmission line outages. Especially, for largescale intermittent energy networks, energy storage device systems can reduce grid instability caused by intermittent energy output, when controlled to achieve an appropriate dynamic response.

There are many kinds of battery energy storage, which are divided into those most suitable for energy shifting applications and those most suitable for high-power applications, with different price dependence on the energy storage capacity $(\mathrm{kWh})$ and the charge and discharge rate $(\mathrm{kW})$. Currently, large-scale application of batteries is restricted by their price in comparison to the economics of their application areas, in this case the active distribution networks. Li-ion, NaS and VRB are three mainstream batteries in the present market, and they have distinctive features and advantages. Li-ion battery has the good features of high power density and no memory effect; NaS battery can discharge with high output power and large current; VRB is cost-effective for large energy capacity and very long life due to no chemical change and electrolyte. This paper evaluates the economics of the three energy storage systems in typical operating conditions and configurations of active distribution networks.

\section{Understanding typical operating conditions}

\subsection{Wind resources in Chongming Island}

Chongming Island in Shanghai, China is assumed to represent the typical condition of intermittent wind power since it is rich in wind resources.

The annual average wind power density of this region at $50 \mathrm{~m}$ high is $339.1 \mathrm{~W} / \mathrm{m}^{2}$, which is much higher than $150 \mathrm{~W} / \mathrm{m}^{2}$, the level normally required for wind energy to be extracted efficiently. In the island, the total capacity of wind power that may be installed is up to $1500 \mathrm{MW}$, and if the average utilization time of wind is 2000 hours per year (or $23 \%$ capacity factor), the achievable energy generation is $3 \mathrm{TWh}$ per year or more, which would be equivalent to the largest wind farms in the world. Cost-effective development of wind power will occur where the average utilization time of wind exceeds 2000 hours per year, so that the generated electricity is greater than or equal to $1.2 \mathrm{GWh}$ for a wind turbine with $600 \mathrm{~kW}$ capacity. When the average utilization time reaches 2500 hours per year, it may be economic to develop wind farms rather than individual turbine installations. In Chongming Island, the annual duration of effective wind is 8418 hours and the average utilization time is 2208 hours per year. In addition, the peak wind speed and peak wind power density both coincide with the peak period of residential electric load each day. According to studies, it is advantageous to mitigate the peak electric load though the use of wind power at 18:00 of August, coinciding with the strongest wind generation [14]. 
Table 1 Amount of installed capacity and power generation of thermal power and wind power under different percent of wind power

\begin{tabular}{|c|c|c|c|c|c|}
\hline \multirow[t]{2}{*}{ Condition } & \multirow[t]{2}{*}{ Percent of wind power $(\%)$} & \multicolumn{2}{|c|}{ Installed capacity (MW) } & \multicolumn{2}{|c|}{ Power generation (TWh) } \\
\hline & & Thermal turbines & Wind turbines & Thermal power & Wind power \\
\hline 1 & - & 570 & - & 3.5 & - \\
\hline 2 & 30 & 480 & 505 & 2.45 & 1.05 \\
\hline 3 & 50 & 355 & 845 & 1.75 & 1.75 \\
\hline 4 & 70 & 242 & 1180 & 1.05 & 2.45 \\
\hline 5 & 100 & 0 & 1688 & 0 & 3.5 \\
\hline
\end{tabular}

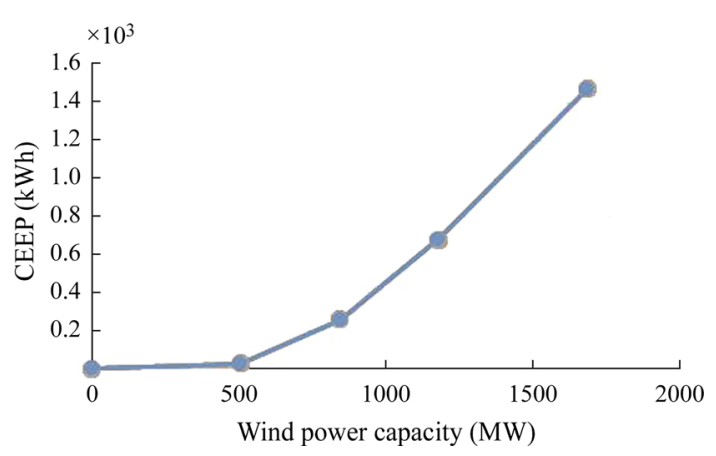

Fig. 1 CEEP with increasing of installed wind capacity when there is no battery energy storage system

\subsection{Energy mix in Chongming Island}

According to the comprehensive analysis of the statistical data in recent years, in this paper the region's peak load is $364 \mathrm{MW}$, and the annual consumption and losses are about $1570 \mathrm{GWh}$, where the power generation is $1238 \mathrm{GWh}$ [15]. The difference of $332 \mathrm{GWh}$ is imported using the power transmission capacity of $250 \mathrm{MW}$ from Jiangsu power grid, supplying about $20.5 \%$ of the total annual electricity consumption. The total installed power plant capacity is $204.5 \mathrm{MW}$ [16], of which the coal-fired power plant is $89.9 \%$, wind farms are $9.5 \%$, and photovoltaic arrays are only $0.6 \%$. The maximum power capacity is $454.5 \mathrm{MW}$.

The intermittent energy generation in the island mainly comprises: (1) $380 \mathrm{~V}$ photovoltaic power plants at some office buildings and other small-scale photovoltaic power generation not connected to the electricity grid; (2) a $10 \mathrm{kV}$ photovoltaic power plants with rated capacity of $1.04 \mathrm{MW}$, and annual generation capacity of $1.05 \mathrm{GWh}$; (3) a $35 \mathrm{kV}$ wind farm: there are 13 turbines with unit capacity of 1.5 MW, hence total capacity of $19.5 \mathrm{MW}$.

\subsection{Energy system based on an active distribution networks}

In 2020, the active distribution network in this region should be completed. According to the goal of eco-island construction (2010-2020) for the island, a gas power plant project was started, located in the south of the Yangtze River at the central region, in order to reduce the energy production and greenhouse gas emissions from the city. The predicted maximum load is set as $1500 \mathrm{MW}$ and the annual electricity consumption is set as $3500 \mathrm{GWh}$ in 2020 according to the moderate prediction scheme of this region [17].

In order to reduce $\mathrm{CO}_{2}$ emissions, the proportion of wind energy is gradually increased from $0 \%$ to $30 \%, 50 \%$, $70 \%, 90 \%$ and $100 \%$ of electricity consumption. To reach very high proportions of wind energy, the availability of wind power should reach 8760 (8784) hours per (leap) year, and this requirements allows the necessary installed capacity and energy generation of thermal power and wind power under different proportions of wind power, as shown in Table 1.

As shown in Table 1, if the demand for electricity is totally supplied by wind power, wind power capacity must be increased at a greater rate than would be required for thermal power capacity. Although it hardly happens now, the condition 5 is studied as an extreme case.

\subsection{CEEP based on an active distribution networks}

As shown in Fig. 1, adding a high proportion of wind power creates a problem of energy systems. Because of the imbalance between the demand and intermittent supply of electricity, wind power is unable to completely supply the grid demand due to instability of wind power, resulting in CEEP of energy systems represented by curtailed wind. When there is excess capacity, many turbines are turned off, and some units of the coal-based energy system must run continuously to ensure the stability of power grid. In this case, compared with refurbished plant and improved energy efficiency, enhancing the ability to coordinate the intermittent wind energy is a better method to reduce greenhouse gas emissions and increase economic benefit, which could be achieved by applying energy storage technologies in an active distribution network. 


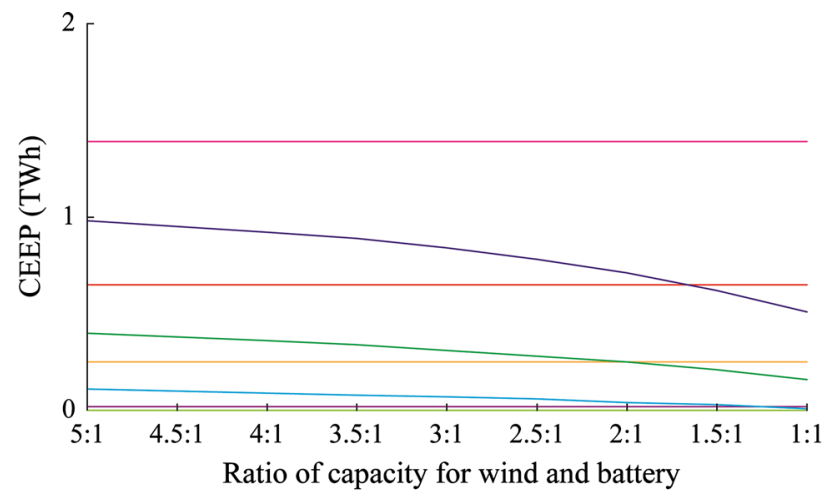

(a) $\mathrm{NaS}$

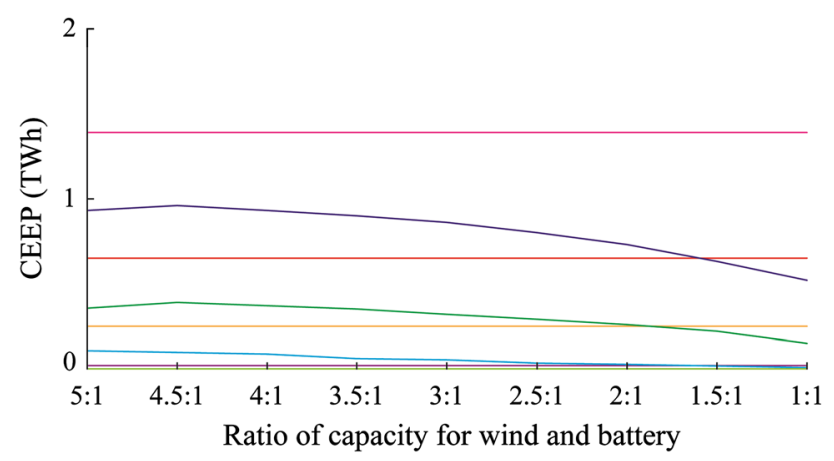

(b) Li-ion

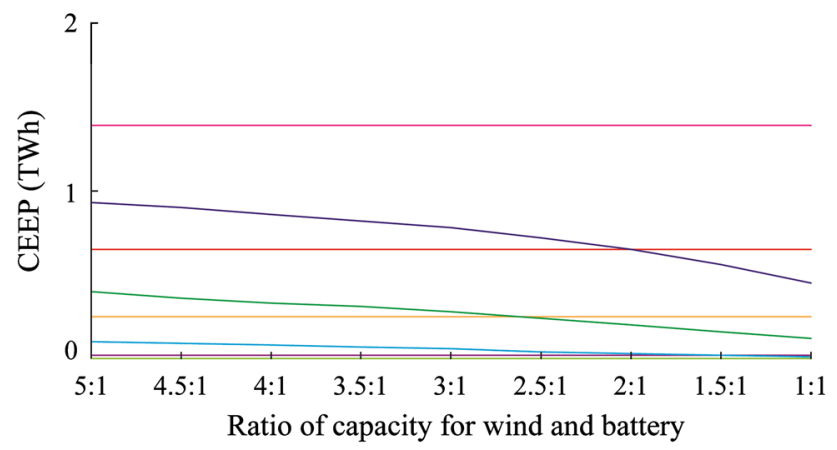

(c) VRB

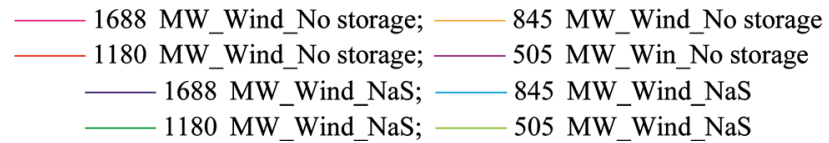

Fig. 2 Impacts on CEEP between wind power and storage capacity

\section{Economic benefits of wind-battery power storage system}

Considering the energy storage system as the principle balancing mechanism of active distribution networks, its capacity and configuration have been researched to make the wind power output smooth and efficiently matched to the load.

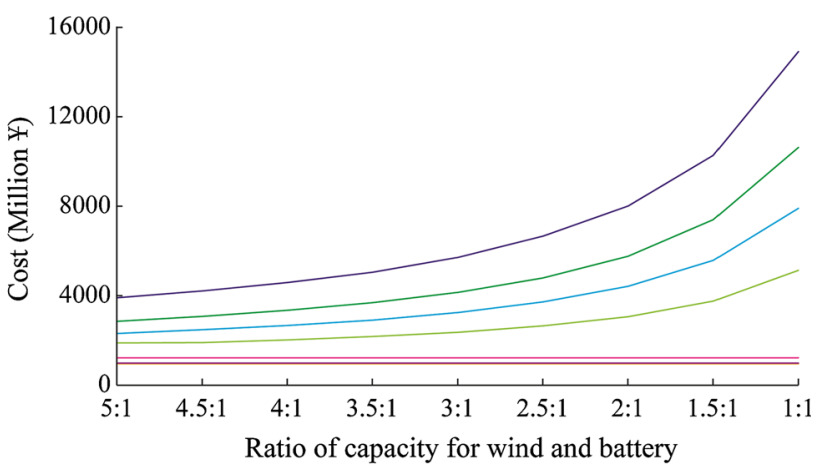

(a) $\mathrm{NaS}$

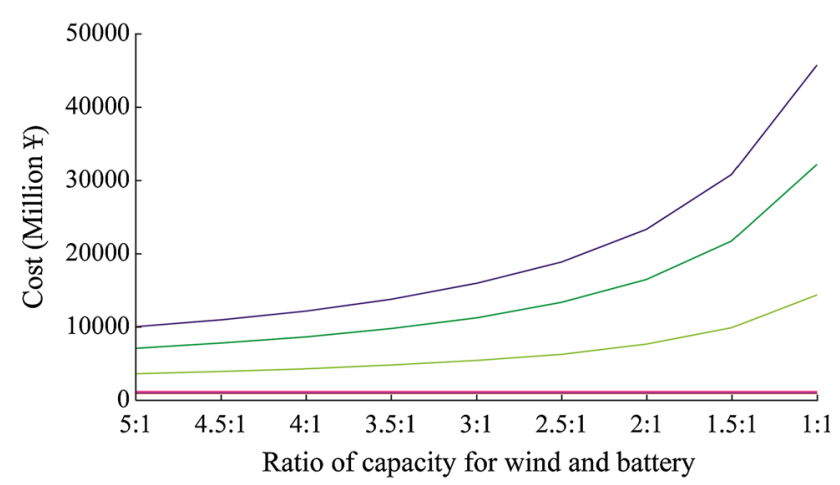

(b) Li-ion

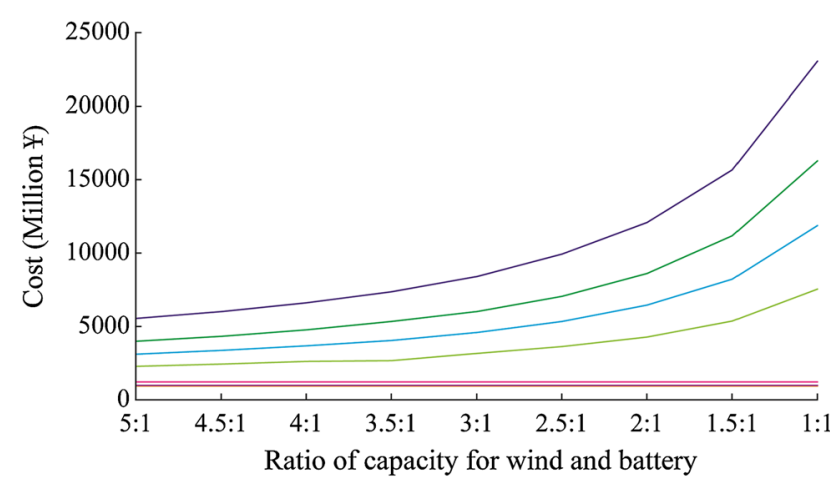

(c) VRB

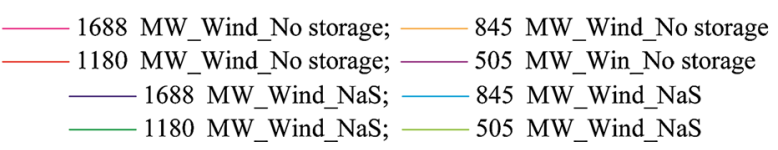

Fig. 3 Impact of wind power installed capacity and energy storage capacity for total annual cost of the energy system TAC

\subsection{Excess capacity (CEEP) of wind-battery power storage system}

Fig. 2 shows the comparative effect on CEEP between different levels of wind power and storage capacity in energy systems composed of thermal power and wind power. The installed capacity of wind power is $505 \mathrm{MW}$, 
$845 \mathrm{MW}, 1180 \mathrm{MW}$, and $1688 \mathrm{MW}$, and the total installed capacity of thermal power is shown in Table 1 . A reference configuration with no storage is also included.

It can be seen that when the installed capacity of wind power was $505 \mathrm{MW}, 845 \mathrm{MW}$ and $1180 \mathrm{MW}$, the value of CEEP significantly improves even when the capacity ratio was 5:1 for wind:battery, while as the proportion of the energy storage capacity increased, the value of CEEP gradually decreased, which indicates the effectiveness of the energy storage system in reducing excess generating capacity and keeping the power grid stable. For different storage systems, the order of decreasing value of CEEP was lithium-ion batteries, sodium sulfur batteries, and vanadium redox flow batteries.

When the wind power capacity is $505 \mathrm{MW}$, the values of CEEP with different types of energy storage system are all close to zero. There is no CEEP after meeting the local load demand for electricity due to the small installed capacity of wind power, and energy storage systems are not required for economic optimization. When the wind power capacity is $1688 \mathrm{MW}$, a large number of wind energy cannot be absorbed by the power grid, and this provides an economic incentive to use energy storage systems.

For the sodium-sulfur battery, as the ratio between wind power and batteries changes from 5:1 to 2:1, the curve of CEEP shows a slow decreasing tendency. As the ratio changes from 2:1 to 1:1, the value of CEEP drops by the largest amount, and when the ratio of wind power and batteries reaches to $1: 1$, the value of CEEP is reduced by more than half. Therefore, the ratio of wind power and sodium sulfur battery energy system should be less than 2:1 in order to efficiently reduce the CEEP value. But for the lithium ion battery, the curve of CEEP also shows a slow decreasing tendency as the ratio of wind power and batteries changes from 5:1 to 3:1. Due to the increased energy storage capacity, the value of CEEP drops by the largest margin as the ratio of wind power and batteries changes from 2.5:1 to $1: 1$, and when the ratio reaches $1: 1$, the value of CEEP decreases by nearly $70 \%$. Therefore, the ratio of wind power and lithium ion battery energy system should be less than $2.5: 1$ to $2: 1$. It is the same to the vanadium redox flow battery.

\subsection{Cost of wind-battery power storage system}

The impact of wind power installed capacity and energy storage capacity on the total annual cost of the energy system (total annual costs TAC) is shown in Fig. 3. Obviously, the overall cost of the system increases due to the battery storage system, and is much higher than the total cost without energy storage system.

Through an analysis of economic viability, when the ratio of wind power and sodium sulfur battery energy system reaches $2.5: 1$, the total annual cost is gradually increased. Meanwhile, the cost of lithium ion battery and vanadium redox flow battery increase sharply, and will not be commercially viable, when the ratio of wind power and battery is greater than $2: 1-1.5: 1$.

\section{Conclusions}

The CEEP and the total annual cost of an example energy storage system were calculated and analyzed for three kinds of battery energy storage system: lithium ion batteries, sodium sulfur batteries, and vanadium redox flow batteries. Proportions of wind energy between $0 \%$ and $100 \%$ were considered, the remainder of load being met by thermal generation, thus an energy system comprising $100 \%$ intermittent energy was included as an extreme case. The results show that the optimum ratio of wind power and battery is $2.5: 1-2: 1$ for the three types of battery under certain wind capacity. The lithium ion battery has the strongest ability to reduce the CEEP, resulting in energy savings and emission reductions, but the total cost is much higher than the other two, which limits its large-scale application. The comprehensive performance of the sodium sulfur battery is best, due to its longer life, and its stronger economic and environmental benefits. Our work will continue to research complex energy storage systems including an economic benefits model, their applications, and their optimal power and capacity to meet the requirements of active distribution networks.

Acknowledgements This work was supported by the National High Technology Research and Development Program of China (863 Program) (No. 2012AA050212).

Open Access This article is distributed under the terms of the Creative Commons Attribution 4.0 International License (http:// creativecommons.org/licenses/by/4.0/), which permits unrestricted use, distribution, and reproduction in any medium, provided you give appropriate credit to the original author(s) and the source, provide a link to the Creative Commons license, and indicate if changes were made.

\section{References}

[1] Cheng DP (2012) Analysis on energy storage technology and its capacity rational allocation in smart power network. Distrib Util 29(5):1-7 (in Chinese)

[2] Lund H (2007) Energy PLAN: advanced energy system analysis computer model. http://www.energyplan.eu/

[3] Lund H, Duić N, Krajačić G et al (2007) Two energy system analysis models: a comparison of methodologies and results. Energy 32(6):948-954

[4] Krajačić G, Duić N, Zmijarević Z et al (2011) Planning for a $100 \%$ independent energy system based on smart energy storage 
for integration of renewables and $\mathrm{CO}_{2}$ emissions reduction. Appl Therm Eng 31(13):2073-2083

[5] Lund H (2005) Large-scale integration of wind power into different energy systems. Energy 30(13):2402-2412

[6] Liu W, Lund H, Mathiesen BV (2011) Large-scale integration of wind power into the existing Chinese energy system. Energy $6(8): 4753-4760$

[7] Lund H (2006) Large-scale integration of optimal combinations of PV, wind and wave power into the electricity supply. Renew Energy 31(4):503-515

[8] Lund H, Münster E (2003) Management of surplus electricityproduction from a fluctuating renewable-energy source. Appl Energy 76(1/2/3):65-74

[9] Lund H, Kempton W (2008) Integration of renewable energy into the transport and electricity sectors through V2G. Energy Policy 36(9):3578-3587

[10] Mathiesen BV, Lund H (2009) Comparative analyses of seven technologies to facilitate the integration of fluctuating renewable energy sources. IET Renew Power Gener 3(2):190-204

[11] Blarke MB, Lund H (2008) The effectiveness of storage and relocation options in renewable energy systems. Renew Energy 33(7):1499-1507

[12] Lund H (2010) Renewable energy systems: the choice and modeling of $100 \%$ renewable solutions. Academic, London

[13] D'Adamo C, Abbey C, Lupe S et al. (2011) Development and operation of active distribution networks: results of CIGRE C6.11 Working Group. In: Proceedings of the 21st international conference on electricity distribution, Frankfurt, 6-9 June 2011, p0311/1-4

[14] SChongming Eco-Island Construction Program (2010-2020) Shanghai's Development and Reform Bureau, Shanghai, China, 2012 (in Chinese)

[15] Yu YF, Roddy D, Ma L (2009) Study of renewable energy utilization in Chongming three islands. Shanghai Electr Power 3:173-178 (in Chinese)

[16] Fan B, Wang H, Yang DS (2012) Analysis of the harmonious in Chongming power grid connected with distributed resources. Power Energy 33(2):169-173

[17] Chongming ecological island development platform. Shanghai Municipal Government, Shanghai, China, 2009 (in Chinese)

Jiongcong CHEN received his M.S. in North China Electric Power University. He is a Ph.D. candidate of South China University of Technology. Meanwhile, he is still working in Smart Grid Department of Electric Power Research Institute of Guangdong Power Grid Co. Ltd. His research interests include smart grid and renewable energy.

Xudong SONG received his M.S. and Ph.D. degree in the school of Electrical Engineering of Wuhan University. Now he is working in Smart Grid Department of Electric Power Research Institute of Guangdong Power Grid Co. Ltd. His research interests include smart grid and renewable energy. 